\title{
Training in pediatric anesthesia in Japan: how should we come along?
}

\author{
Soichiro Obara ${ }^{1,2} \mathbb{D} \cdot$ Norifumi Kuratani $i^{2,3}$ \\ Received: 2 August 2020 / Accepted: 19 September 2020 / Published online: 3 October 2020 \\ (c) Japanese Society of Anesthesiologists 2020
}

Keywords Pediatric anesthesia $\cdot$ Training $\cdot$ Caseload $\cdot$ Volume-outcome relationship $\cdot$ Simulation

\section{Introduction}

The potential long-term impact of surgery and anesthesia has been progressing over the past 20 years with a significant interest and academically challenging research activity on the several aspects of neurodevelopment [1,2]. Although anesthesiologists are currently facing the likelihood that detectable developmental anesthetic neurotoxicity may not exist in a single and short exposure to general anesthesia in early life [3-6], they have not yet been able to prove or disprove this nonexistence [7].

In addition to long-term neurodevelopmental outcome, anesthesiologists still need to pay sufficient attention to immediate perioperative risks. Pediatric anesthesia-related mortality has decreased to approximately 1 out of 10,000 children who receive anesthetics $(0.01 \%)$ in high-income countries [8-13]. However, the rates of pediatric anesthesiarelated severe adverse events remaining approximately $2-8 \%$ even in high-income countries [12-16]. A recent prospective cohort study, the Anesthesia Practice in Children Observational Trial (APRICOT), revealed a relatively high overall incidence $(5.2 \%)$ of perioperative severe adverse events with large variability in anesthetic practices across 33 European countries [17].

Subsequently, there are rising trends of minimally invasive surgeries including robotic surgery [18] and sedation or anesthesia outside the operating room [19-21]. Although

Soichiro Obara

soichoba1975@gmail.com

1 Department of Anesthesia, Tokyo Metropolitan Ohtsuka Hospital, 2-8-1, Minami-ohtsuka, Toshima-ku, Tokyo 170-8476, Japan

2 Teikyo University Graduate School of Public Health, Tokyo, Japan

3 Department of Anesthesia, Saitama Children's Medical Center, Saitama, Japan these practices are not different in pediatric and adult patients, they may offer unique challenges, requiring the anesthesiologists' scrupulous knowledge and comprehension on the associated anatomical and physiological considerations in pediatric patients [22].

Given the challenges observed in studies related to anesthetic impact on neurodevelopment, children offer unique opportunities for anesthesiologists to consider lifelong consequences of any early intervention. Pediatric perioperative issues are facing challenges which require sustained efforts from anesthesiologists. However, training in pediatric anesthesia is reaching a turning point in Japan.

\section{Volume-outcome association in pediatric anesthesia}

Training in the field of anesthesia is generally implemented, which comprises direct teaching, targeted supervision, and overall acquisition of knowledge, skills, and attitudes essential to the safe and effective delivery of anesthesia [23]. Basically, the more you are trained, the more you can advance from a novice to a competent trainee. Hence, training is the predominant factor determining the advancement from a novice to a competent trainee. However, higher-level development to an expert requires an additional challenge, such as experiences. In short, experience consolidates knowledge and helps to establish safe practice [24].

A previous French postal survey reported the association between the number of anesthesia-related complications and the volume of pediatric anesthetic practices per year, showing less caseloads per anesthesia provider were associated with more postoperative complications [25]. The APRICOT has also shown that senior anesthesiologists had $1 \%$ fewer critical respiratory events per year of experience and that facilities with a higher caseload had a lower rate of critical events [17]. A sub-analysis using the UK data only in the 
APRICOT demonstrated that the lower incidence of cardiovascular and respiratory complications could be partly attributed to more experienced dedicated pediatric anesthesia providers managing the higher-risk patients, whereas it did not show significant inverse volume-outcome effects in perioperative critical events among institutions [26]. Hence, controversies in volume-outcome association per anesthesia provider or per institution in terms of the incidence of perioperative adverse events exist. However, some experts recommended a minimum caseload of 200 pediatric anesthesia practices per provider per year to reduce the incidence of complications [25]. Practically, setting a minimum caseload volume is considered complicated, and the exact number is difficult to define and apply for all pediatric anesthetic procedures.

\section{Recent changes impacting on anesthesia training in Japan}

Training in pediatric anesthesia has recently experienced significant organizational and politically driven changes in Japan.

One change is the introduction of compulsory pediatric anesthesia training as well as cardiac, thoracic, neurosurgi$\mathrm{cal}$, and obstetric anesthesia training as a prerequisite for the anesthesia board examination. During the 4-year anesthesiology residency, all anesthesiology trainees need to provide anesthesia for at least 600 cases. In the 600 cases, a minimum number is set for each specialty: the number of compulsory pediatric cases is 25 for children aged less than 6 years. Every university hospital has been required to plan pediatric anesthesia training programs, and simultaneously, children's hospitals have been required to be restructured to meet the changing educational demands. Among the minimum required number of pediatric cases in anesthesiology trainees in the USA, Europe, and Japan, that in Japan seems to be the most limited [27]. There is a wide variability in the number of procedures performed among anesthesiology trainees until acceptable safe anesthetic procedures are attained [28]. Therefore, it would be difficult to define the "magic number" for anesthesiology trainees to attain sufficient knowledge and skills to provide safe pediatric anesthetic practices. However, the minimum caseload of 25 pediatric anesthetic practices during residency may be insufficient for an anesthesiologist to comfortably provide care even for children with ASA-PS class I or II [29].

Another change in anesthesia training, not only in pediatric but also in general, is that the introduction of the Japanese Working Time Directive ("Work Style Reform" policy) will predominantly result in reduced total weekly hours even for medical trainees in the future. It must help us maintain the quality of life of medical practitioners. On the contrary, it may reduce the total time of exposure of anesthesiology trainees to clinical pediatric anesthesia cases. Practically, extending the hours worked or the length of training programs is not necessarily a sustainable solution for anesthesiology training. The concept of "making every moment count" is important. Meanwhile, lack of experiences and clinical exposures may result in less independent practices and loss of self-confidence of anesthesiologist trainees, eventually leading to increasing perioperative complications and growing concerns over patient safety $[17,25,26]$.

\section{Possible lower caseload per anesthesia provider in the future}

In addition to the likely reduced working hours, there are other issues that may also have an impact on the caseload of pediatric anesthetic practices per provider.

One is a demographic change toward super-aging society with fewer children. The decrease in the fertility rate and marriage rate has accelerated a shrinking, aging population with fewer children in Japan [30]. Hence, Japan has focused its policies on the work-life balance to increase the birth rate with the introduction of the Japanese Working Time Directive in 2010.

Another is the underdevelopment of centralized medical resources and services for children in Japan. Regionalization of medical resources and services could provide anesthesiology trainees more clinical exposure if they are trained in large centers. However, regionalization has not been well developed in Japan. The infant mortality rate in Japan has been significantly low due to the extensive endeavors of people engaged in executing Japanese policies on maternal and child health since World War II. The low infant mortality rate has been attributed partly to easy access to medical care due to the spatial distribution of small-scale hospitals located to adjacent to dwellings, a well-organized national health insurance system, and inexpensive medical fees [31]. On the contrary, these factors could cause less accumulation of experience per pediatric practitioner [31]. Therefore, the Japan Pediatric Society has proposed the innovative model, which includes regionalization of medical resources. Under this changing circumstances, we have not yet had any definite data based on an anesthesiology workforce analysis in Japan, which should project pediatric anesthesia case-topediatric population ratios [32].

\section{Future perspective: new training model and large data analyses}

We need to think about innovation of the concept of training model to conquer the possible issue of lower caseload volume. The existing training model emphasizes the quantity 
and number of fragmented inputs. However, given the lower caseload volume, we may need to change the model to emphasize the quality and value of inputs with integration under the concept of "making every moment count."

A growing trend in evidence-based medicine is the desire to reduce unnecessary interventions and decrease iatrogenic complications which is undoubtedly better for patient care. In the context of possibly lowering caseload, limiting working hours and decreasing procedure necessity, simulationbased training will be more prioritized. Recent systematic review indicates that simulation training in anesthesia is at least as good as non-simulator training, and is certainly better than no intervention [33]. There is ongoing enthusiasm for simulation-based training in pediatric anesthesia [34-39]. In the era of information technology, telesimulation may provide an alternative method to traditional simulation approaches [40, 41], though simulation-based training in anesthesia is fraught with challenges, such as relatively high cost, faculty development, and less tangible patient outcomes [42-46].

In summary, possible lower caseload can be considered a challenge in pediatric anesthesia training in Japan, leading to increased morbidity in the perioperative care of children. Now, we need to consider general approaches to maintain the academic and professional standards in pediatric anesthesia despite the introduction of changed working patterns and reduced hours over the next decade in super-aging society with fewer children. Before then, research projects are expected to comprehend the basic indices, such as perioperative pediatric morbidity and mortality [47] and pediatric anesthesiology workforce survey [32], which require data mining and analytics $[48,49]$.

\section{Compliance with ethical standards}

Conflict of interest The authors declare that they have no conflict of interest.

\section{References}

1. Wu L, Zhao H, Weng H, Ma D. Lasting effects of general anesthetics on the brain in the young and elderly: "mixed picture" of neurotoxicity, neuroprotection and cognitive impairment. J Anesth. 2019;33:321-35.

2. Liu X, Ji J, Zhao G-Q. General anesthesia affecting on developing brain: evidence from animal to clinical research. J Anesth. 2020;34:767-72.

3. Sun LS, Li G, Miller TLK, Salorio C, Byrne MW, Bellinger DC, Ing C, Park R, Radcliffe J, Hays SR, DiMaggio CJ, Cooper TJ, Rauh V, Maxwell LG, Youn A, McGowan FX. Association between a single general anesthesia exposure before age 36 months and neurocognitive outcomes in later childhood. JAMA. 2016;315:2312-20.
4. Warner DO, Zaccariello MJ, Katusic SK, Schroeder DR, Hanson AC, Schulte PJ, Buenvenida SL, Gleich SJ, Wilder RT, Sprung J, Hu D, Voigt RG, Paule MG, Chelonis JJ, Flick RP. Neuropsychological and behavioral outcomes after exposure of young children to procedures requiring general anesthesia: the mayo anesthesia safety in kids (MASK) study. Anesthesiology. 2018;129:89-105.

5. Davidson AJ, Disma N, de Graaff JC, Withington DE, Dorris L, Bell G, Stargatt R, Bellinger DC, Schuster T, Arnup SJ, Hardy P, Hunt RW, Takagi MJ, Giribaldi G, Hartmann PL, Salvo I, Morton NS, von Ungern Sternberg BS, Locatelli BG, Wilton N, Lynn A, Thomas JJ, Polaner D, Bagshaw O, Szmuk P, Absalom AR, Frawley G, Berde C, Ormond GD, Marmor J, McCann ME. Neurodevelopmental outcome at 2 years of age after general anaesthesia and awake-regional anaesthesia in infancy (GAS): an international multicentre, randomised controlled trial. Lancet. 2016;387:239-50.

6. McCann ME, de Graaff JC, Dorris L, Disma N, Withington D, Bell G, Grobler A, Stargatt R, Hunt RW, Sheppard SJ, Marmor J, Giribaldi G, Bellinger DC, Hartmann PL, Hardy P, Frawley G, Izzo F, von Ungern Sternberg BS, Lynn A, Wilton N, Mueller M, Polaner DM, Absalom AR, Szmuk P, Morton N, Berde C, Soriano S, Davidson AJ, GAS Consortium. Neurodevelopmental outcome at 5 years of age after general anaesthesia or awake-regional anaesthesia in infancy (GAS): an international, multicentre, randomised, controlled equivalence trial. Lancet. 2019;393:664-77.

7. Vutskits L, Culley DJ. GAS, PANDA, and MASAK: no evidence of clinical anesthetic neurotoxicity! Anesthesiology. 2019;131:762-4.

8. Morray JP, Geiduschek JM, Ramamoorthy C, Haberkern CM, Hackel A, Caplan RA, Domino KB, Posner K, Cheney FW. Anesthesia-related cardiac arrest in children: initial findings of the pediatric perioperative cardiac arrest (POCA) registry. Anesthesiology. 2000;93:6-14.

9. Bhananker SM, Ramamoorthy C, Geiduschek JM, Posner KL, Domino KB, Haberkern CM, Campos JS, Morray JP. Anesthesiarelated cardiac arrest in children: update from the pediatric perioperative cardiac arrest registry. Anesth Analg. 2007;105:344-50.

10. Murat I, Constant I, Maud'huy H. Perioperative anaesthetic morbidity in children: a database of 24,165 anaesthetics over a 30-month period. Pediatr Anesth. 2004;14:158-66.

11. Irita K, Tsuzaki K, Sawa T, Sanuki M, Nakatsuka H, Makita K, Morita K. The state of pediatric anesthesia in Japan: an analysis of the Japanese Society of Anesthesiologists survey of critical incidents in the operating room. Masui (Jpn J Anesthesiol). 2007;56:93-102 (in Japanese with English abstract).

12. Gonzalez LP, Pignaton W, Kusano PS, Módolo NSP, Braz JRC, Braz LG. Anesthesia-related mortality in pediatric patients: a systematic review. Clinics (Sao Paulo). 2012;67:381-7.

13. Cronje L. A review of paediatric anaesthetic-related mortality, serious adverse events and critical incidents. South Afr J Anaesth Analg. 2015;21:147-53.

14. MacLennan AI, Smith AF. An analysis of critical incidents relevant to pediatric anesthesia reported to the UK national reporting and learning system, 2006-2008. Pediatr Anesth. 2011;21:841-7.

15. de Graaff JC, Sarfo MC, van Wolfswinkel L, van der Werff DBM, Schouten ANJ. Anesthesia-related critical incidents in the perioperative period in children; a proposal for an anesthesia-related reporting system for critical incidents in children. Pediatr Anesth. 2015;25:621-9.

16. Williams GD, Muffly MK, Mendoza JM, Wixson N, Leong K, Claure RE. Reporting of perioperative adverse events by pediatric anesthesiologists at a tertiary children's hospital: targeted interventions to increase the rate of reporting. Anesth Analg. 2017;125:1515-23. 
17. Habre W, Disma N, Virag K, Becke K, Hansen TG, Jöhr M, Leva B, Morton NS, Vermeulen PM, Zielinska M, Boda K, Veyckemans F, APRICOT Group of the European Society of Anaesthesiology Clinical Trial Network. Incidence of severe critical events in paediatric anaesthesia (APRICOT): a prospective multicenter observational study in 261 hospitals in Europe. Lancet Respir Med. 2017;5:412-25.

18. Mishra P, Gupta B, Nath A. Anesthetic considerations and goals in robotic pediatric surgery: a narrative review. J Anesth. 2020;34:286-93.

19. Komasawa N, Fujiwara S, Atagi K, Ueki R, Haba M, Ueshima $\mathrm{H}$, Kaminoh Y, Minami T. Effects of a simulation-based sedation training course on non-anesthesiologists' attitudes toward sedation and analgesia. J Anesth. 2014;28:785-9.

20. Ben-Ari M, Chayen G, Steiner IP, Schinasi DA, Feldman O, Shavit I. The effect of in situ simulation training on the performance of tasks related to patient safety during sedation. J Anesth. 2018;32:300-4.

21. Nagrebetsky A, Gabriel RA, Dutton RP, Urman RD. Growth of nonoperating room anesthesia care in the United States: a contemporary trends analysis. Anesth Analg. 2017;124:1261-7.

22. Wong T, Georgiadis PL, Urman RD, Tsai MH. Non-operating room anesthesia: patient selection and special considerations. Local Reg Anesth. 2020;13:1-9.

23. Tetzlaff JE. Assessment of competency in anesthesiology. Anesthesiology. 2007;106:812-25.

24. McIndoe AK. Modern anaesthesia training: is it good enough? Br J Anaesth. 2012;109:16-20.

25. Auroy Y, Ecoffey C, Messiah A, Rouvier B. Relationship between complications of pediatric anesthesia and volume of pediatric anesthetics. Anesth Analg. 1997;84:234-5.

26. Engelhardt T, Ayansina D, Bell GT, Oshan V, Rutherford JS, Morton NS, APRICOT Group of the European Society of Anaesthesiology Clinical Trial Network. Incidence of severe critical events in paediatric anaesthesia in the United Kingdom: secondary analysis of the anaesthesia practice in children observational trial (APRICOT study). Anaesthesia. 2019;74:300-11.

27. Viola L, Clay S, Samuels P. Education in pediatric anesthesiology: competency, innovation, and professionalism in the 21 st century. Int Anesthesiol Clin. 2012;50:1-12.

28. Konrad C, Schüpfer G, Wietlisbach M, Gelber H. Learning manual skills in anesthesiology: is there a recommended number of cases for anesthetic procedures? Anesth Analg. 1998;86:635-9.

29. Shimada Y, Nishikawa K, Sato K, Sato E, Miyasaka K. Pediatric anesthesia practice and training in Japan: a survey. Pediatr Anesth. 2006;16(5):543-7.

30. Nomura K, Karita K, Araki A, Nishioka E, Muto G, Iwai-Shimada M, Nishikitani M, Inoue M, Tsurugano S, Kitano N, Tsuji M, Iijima S, Ueda K, Kamijima M, Yamagata Z, Sakata K, Iki M, Yanagisawa H, Kato M, Inadera H, Kokubo Y, Yokoyama K, Koizumi A, Otsuki T. For making a declaration of countermeasures against the falling birth rate from the Japanese Society for Hygiene: summary of discussion in the working group on academic research strategy against an aging society with low birth rate. Environ Health Prev Med. 2019;24:14.

31. Bessho F. Achievement of child health and welfare in Japan and current problems faced. JMAJ. 2007;50:471-3.

32. Muffly MK, Singleton M, Agarwal R, Scheinker D, Miller D, Muffly TM, Honkanen A. The pediatric anesthesiology workforce: projecting supply and trends 2015-2035. Anesth Analg. 2018;126:568-78.
33. Lorello GR, Cook DA, Johnson RL, Brydges R. Simulation-based training in anaesthesiology: a systematic review and meta-analysis. Br J Anaesth. 2014;112:231-45.

34. Everett TC, MacKinnon R, de Beer D, Taylor M, Bould MD. Ten years of simulation-based training in pediatric anesthesia: the inception, evolution, and dissemination of the Managing Emergencies in Pediatric Anesthesia (MEPA) course. Pediatr Anesth. 2017;27:984-90.

35. Everett TC, McKinnon RJ, Ng E, Kulkarni P, Borges BCR, Letal M, Fleming M, Bould MD, MEPA Collaborators. Simulationbased assessment in anesthesia: an international multicentre validation study. Can J Anaesth. 2019;66:1440-9.

36. Boyd N, Sharkey E, Nabukenya M, Tumukunde J, Sipuka N, Zyambo M, Walker I, Hart J, Byrne-Davis L. The Safer Anaesthesia from Education $(\mathrm{SAFE})^{\circledR}$ paediatric anaesthesia course: educational impact in five countries in East and Central Africa. Anaesthesia. 2019;74:1290-7.

37. Ambardekar AP, Singh D, Lockman JL, Rodgers DL, Hales RL, Gurnaney HG, Nathan A, Deutsch ES. Pediatric anesthesiology fellow education: is a simulation-based boot camp feasible and valuable? Pediatr Anesth. 2016;26(5):481-7.

38. Ambardekar AP, Black S, Singh D, Lockman JL, Simpao AF, Schwartz AJ, Hales RL, Rodgers DL, Gurnaney HG. The impact of simulation-based medical education on resident management of emergencies in pediatric anesthesiology. Pediatr Anesth. 2019;29:753-9.

39. Ambardekar AP, Newell A, Blassius K, Waldrop WB, Young DA. Medical simulation utilization among pediatric anesthesiology fellowship programs. Pediatr Anesth. 2020;30:823-32.

40. Ohta K, Kurosawa H, Shiima Y, Ikeyama T, Scott J, Hayes S, Gould M, Buchanan N, Nadkarni V, Nishisaki A. The effectiveness of remote facilitation in simulation-based pediatric resuscitation training for medical students. Pediatr Emerg Care. 2017;33:564-9.

41. Hayden EM, Khatri A, Kelly HR, Yager PH, Salazar GM. Mannequin-based telesimulation: increasing access to simulation-based education. Acad Emerg Med. 2018;25:144-7.

42. Nishisaki A, Keren R, Nadkarni V. Does simulation improve patient safety?: self-efficacy, competence, operational performance, and patient safety. Anesthesiology Clin. 2007;25:225-36.

43. Okuda Y, Bryson EO, DeMaria JS, Jacobson L, Quinones J, Shen $\mathrm{B}$, Levine IA. The utility of simulation in medical education: what is the evidence? Mt Sinai J Med. 2009;76:330-43.

44. Fehr JJ, Honkanen A, Murray DJ. Simulation in pediatric anesthesiology. Pediatr Anesth. 2012;22:988-94.

45. Yang D, Wei Y-K, Xue F-S, Deng X-M, Zhi J. Simulation-based airway management training: application and looking forward. J Anesth. 2016;30:284-9.

46. Yunoki K, Sakai T. The role of simulation training in anesthesiology resident education. J Anesth. 2018;32:425-33.

47. Watters DA, Hollands MJ, Gruen RL, Maoate K, Perndt H, McDougall RJ, Morriss WM, Tangi V, Casey KM, McQueen KM. Perioperative mortality rate (POMR): a global indicator of access to safe surgery and anaesthesia. World J Surg. 2015;39:856-64.

48. Levin MA, Wanderer JP, Ehrenfeld JM. Data, big data, and metadata in anesthesiology. Anesth Analg. 2015;121:1661-7.

49. deGraaff JC, Engelhardt T. How big data shape paediatric anaesthesia. Br J Anaesth. 2017;119:448-51.

Publisher's Note Springer Nature remains neutral with regard to jurisdictional claims in published maps and institutional affiliations. 